\title{
The putative Notch ligand HyJagged is a transmembrane protein present in all cell types of adult Hydra and upregulated at the boundary between bud and parent
}

\author{
Andrea Prexl ${ }^{1}$, Sandra Münder ${ }^{1}$, Bernhard Loy ${ }^{2}$, Elisabeth Kremmer ${ }^{3}$, Susanne Tischer ${ }^{1}$ and Angelika Böttger ${ }^{1 *}$
}

\begin{abstract}
Background: The Notch signalling pathway is conserved in pre-bilaterian animals. In the Cnidarian Hydra it is involved in interstitial stem cell differentiation and in boundary formation during budding. Experimental evidence suggests that in Hydra Notch is activated by presenilin through proteolytic cleavage at the S3 site as in all animals. However, the endogenous ligand for HvNotch has not been described yet.

Results: We have cloned a cDNA from Hydra, which encodes a bona-fide Notch ligand with a conserved domain structure similar to that of Jagged-like Notch ligands from other animals. Hyjagged mRNA is undetectable in adult Hydra by in situ hybridisation but is strongly upregulated and easily visible at the border between bud and parent shortly before bud detachment. In contrast, HyJagged protein is found in all cell types of an adult hydra, where it localises to membranes and endosomes. Co-localisation experiments showed that it is present in the same cells as HvNotch, however not always in the same membrane structures.

Conclusions: The putative Notch ligand HyJagged is conserved in Cnidarians. Together with HvNotch it may be involved in the formation of the parent-bud boundary in Hydra. Moreover, protein distribution of both, HvNotch receptor and HyJagged indicate a more widespread function for these two transmembrane proteins in the adult hydra, which may be regulated by additional factors, possibly involving endocytic pathways.
\end{abstract}

\section{Background}

Early embryonic development is regulated in all animals by common signalling pathways such as the Wnt-, FGF, Hedgehog-, TGF $\beta /$ BMP- and Notch pathways. They have been shown to be present in basal metazoans such as Cnidarians [1-5]. The fresh water polyp Hydra consists of a simple tube-like body made of two epithelial layers, the inner endoderm and the outer ectoderm separated by an acellular mesoglea. It further possesses a hypostome and a ring of tentacles at the apical end and a foot at its basal end. Interstitial cells are located in the spaces between the epithelial cells of both cell layers. They constitute a pluripotent stem cell lineage that differentiates nerve cells, gland cells, germ cells and

\footnotetext{
* Correspondence: bottger@zi.biologie.uni-muenchen.de

'Department of Biology 2, Ludwig-Maximilians-Universität München, Munich, Germany

Full list of author information is available at the end of the article
}

nematocytes. The latter carry nematocyte capsules used for catching prey and are unique to Cnidarians [6-9].

The Notch signalling pathway has recently been shown to be involved in nematocyte and female germ cell differentiation, as well as in budding $[5,10]$. Whilst an inductive function of Notch for terminal differentiation of nematoblasts and oocytes has been suggested the precise mechanisms are completely unclear. During budding Notch signalling was shown to be important for the formation of a sharp boundary between the bud and the parent animal. This seemed to be the preposition for the bud to make a constriction at its base and form a foot. As has been shown at many other developmental boundaries Notch signalling here appears to have the potential to create patterns where two adjacent cells adopt different fates. These are signal receiving cells, which have the Notch receptor, and signal sending cells carrying a Notch ligand. Notch ligands possess a
C Biomed Central

() 2011 Prexl et al; licensee BioMed Central Ltd. This is an Open Access article distributed under the terms of the Creative Commons Attribution License (http://creativecommons.org/licenses/by/2.0), which permits unrestricted use, distribution, and reproduction in any medium, provided the original work is properly cited. 
characteristic domain, the DSL (Delta, Serrate, Lag) domain, followed by several EGF repeats and a transmembrane domain. Serrate/Jagged-like ligands have an extra domain, the cysteine rich von Willebrand type C (VWC) domain, between the EGF repeats and the transmembrane domain. Interaction with Notch receptors takes place via the DSL domains of the ligand and the EGF repeats of the receptor [11].

We have now identified a potential Notch ligand in Hydra. Here we present its sequence and expression pattern. Comparison of its amino acid sequence with that of other Notch ligands of the DSL family shows similarity to Serrate/Jagged-like ligands. We thus named it HyJagged. Its mRNA expression levels in adult animals were not detectable by in situ hybridisation with the exception of a remarkable upregulation at final stages of budding in cells of the parent animal at the site where the bud detaches. However, immunofluorescence studies with anti-HyJagged antibody revealed the presence of HyJagged in all cells of adult animals where it is localised at membranes and in endosomes.

\section{Results}

\section{Isolation and characterization of the Hydra Jagged gene}

Database searches of the Hydra genome [12] led to a core sequence prediction for a DSL protein with similarity to Jagged/Serrate-like Notch ligands. After performing 5' and 3' RACE experiments the full-length Hyjagged sequence was amplified from Hydra cDNA [GenBank:JN036823]. The resulting HyJagged protein sequence is shown in Figure 1 in an alignment with mouse Jagged1. It contains a signal peptide (1-22aa), a DSL (Delta, Serrate, Lag) domain (181-252aa), which is characteristic for Notch ligands (Figure 2) [13], and five EGF repeats (255-540aa). A cysteine rich domain, the von Willebrand type C (VWC) domain (549616aa), is located N-terminally of the transmembrane domain (763-785aa), followed by a short non-conserved intracellular region. Comparison with Notch ligands from worms, insects and vertebrates further shows that the modular structure is conserved in HyJagged (Figure 3). The presence of the von Willebrand type $\mathrm{C}$ domain, which is characteristic for Serrate/Jagged-like ligands, led us to name the Hydra protein HyJagged.

Interestingly, comparison of HyJagged with the predicted sequence of a Notch ligand from the sea anemone Nematostella vectensis, another Cnidarian, shows a generally similar domain structure between the two proteins but also an important difference (Figure 3). The Nematostella gene encodes a protein with 17 EGF repeats, whereas HyJagged has only six, which in both cases nearly matches the number of EGF repeats in their respective Notch receptors. The DSL domains between the Notch ligands from Nematostella and Hydra are also highly conserved (Figure 2).

HyJagged consists of 835 amino acids that are encoded by 16 exons on a stretch of 11.452 nucleotides. Comparison of the gene organisation of mouse jagged 1 with Hyjagged is shown in Figure 4. All exon-intron boundaries are flanked by the conserved GT-AG sequences, 14 of these boundaries appear to be conserved between mouse and Hydra (Figure 4, indicated by arrows). These reflect the modular organisation of Jagged proteins in all animals. Most EGF repeats and the transmembrane domain are encoded by single exons. However the Hydra DSL domain and the mouse VWC domain, as well as the signal peptides of both proteins are encoded within two exons, respectively.

\section{mRNA expression of Hyjagged}

To look for expression of the Hyjagged gene in adult hydra in situ hybridisation experiments were performed. These showed no signal, indicating that Hyjagged is expressed at very low levels in contrast to the expression of HvNotch, which shows very high levels of mRNA all over the animal [5]. This is in accordance with the fact that no ESTs encoding HyJagged could be identified in the libraries.

However, when we looked for Hyjagged mRNA during budding we found a very strong expression of the gene during budding stage 9 . This is when the bud begins to form foot cells. The signal was present in cells of the ectoderm of the parent animal and coincided with the expression zone of the Hydra FGF-receptor homolog kringelchen (Figure 5).

\section{Protein localisation of HyJagged}

In order to study the subcellular distribution of HyJagged in hydra cells the protein was overexpressed as a GFP fusion protein in single cells of intact animals and observed in vivo (Figure 6). For detection of plasma membranes and endosomes the membrane-selective dye FM4-64 was injected into the gastric cavity and the animals were imaged at different time points afterwards. FM4-64 is usually detected at membranes first but is then increasingly enriched in endosomes, which become larger over time [14]. In Figure 6 we show the distribution of FM4-64 in cells of live imaged animals over a period of 20 hours. HyJagged-GFP hardly co-localised with FM4-64 at membranes at the time points indicated. However, it was seen in punctuate and ring-like structures in the cytoplasm. Some of these clearly corresponded to FM4-64 positive structures and thus most likely constituted early and late endosomes. We then compared this HyJagged-GFP distribution with the localisation of HvNotch-RFP in epithelial cells. Figure 7 shows that both proteins are localised in punctuate and 


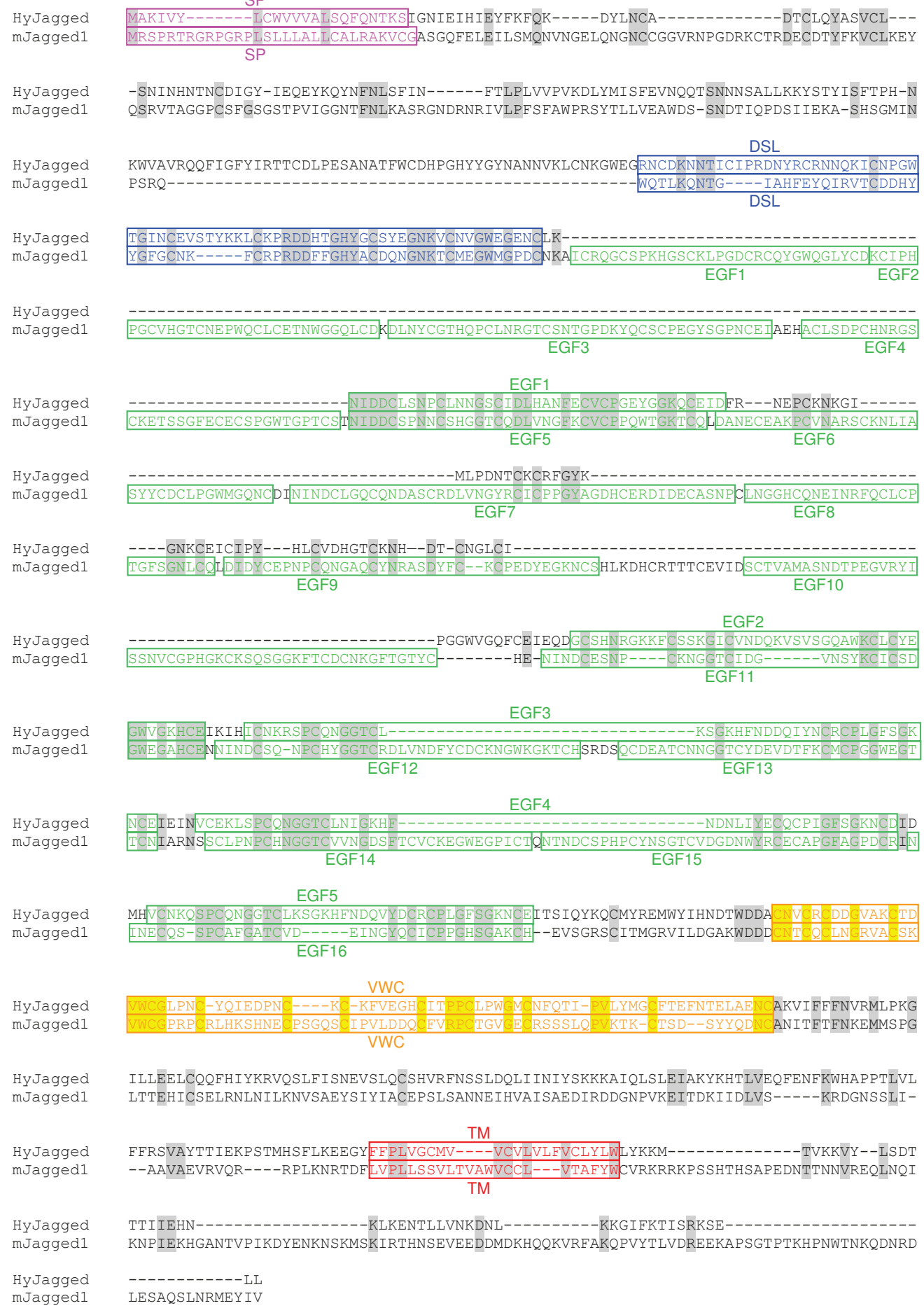

EGF2

SSNVCGPHGKCKS QSGGKETCDCNKGETGTYC------HE-UNINDCESNP----CKNGGTCIDG-----VNSYKCICSD EGF11

HyJagged mJagged1 EGF12 EGF13

HyJagged mJagged1 EGF14 EGF15

EGF5

HyJagged MHVCNKQSPCQNGGTCLKSGKHFNDQVYDCRCPLGESGKNCEITS IQYKQCMYREMWY I HNDTWDDA CNVCRCDDGVAKCTD mJagged1 EGF16

HyJagged mJagged1

HyJagged mJagged1

ILLEELCQQFHIYKRVQSLF ISNEVSLQCSHVRFNSSLDQL I INIYSKKKAIQLSLEIAKYKHTLVEQFENFKWHAPPTLVL LTTEHICSELRNLNILKNVSAEYSIYIACEPSLSANNEIHVAISAEDIRDDGNPVKEITDKIIDLVS-----KRDGNSSLI-

HyJagged mJagged1 FFRSVAYTTIEKPSTMHSFLKEEGY TMFPLVGCMV----VCVLVLFVCLYLWTLYKKM-------------TVKKVY--LSDT

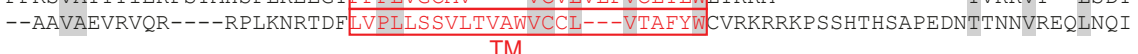

HyJagged

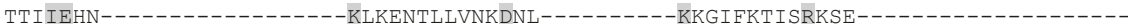
mJagged1 KNPIEKHGANTVPIKDYENKNSKMSKIRTHNSEVEEDDMDKHQQKVRFAKQPVYTLVDREEKAPSGTPTKHPNWTNKQDNRD

HyJagged mJagged1

$----------L L$

Figure 1 Clustal $\mathrm{X}$ alignment of mJagged1 (mouse) and HyJagged (Hydra). Signal peptide (SP, pink), DSL domain (DSL, blue), EGF repeats (EGF, green), WWC domain (VWC, yellow), transmembrane domain (TM, red). Identical amino acids are highlighted in grey and yellow respectively. 


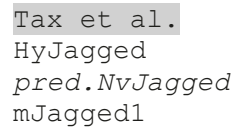

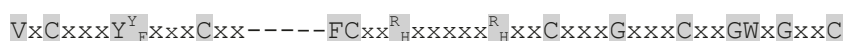
RNCDKNNTICIPRDNYRCRNNQKICNPGWTGINCEVSTYKKLCKPRDDHTGHYGCSYEGNKVCNVGWEGENC WESHSYN-GPTAS IKYNV---RVVCDEHYYGRTCT-----ILCKPRDDIFGHYTCDEQGHKICLPGWRGDHC WQTLKQNTG----IAHFEYQIRVTCDDHYYGFGCN-----KFCRPRDDFFGHYACDQNGNKTCMEGWMGPDC

Figure 2 Alignment of DSL domains from predicted NvJagged (Nematostella), mJagged1 (mouse) and HyJagged (Hydra) in comparison with the DSL domain consensus sequence suggested by Tax et al. [13]. Consensus sequence of DSL domains according to [13]. Identical amino acids are marked in grey.

ring-like structures, however they only partially colocalised.

In the absence of detectable mRNA for the putative Notch ligand Hyjagged we thought to look for the endogenous HyJagged protein. We therefore raised an antibody in rabbit against a synthetic peptide corresponding to 18 amino acids of the intracellular domain of HyJagged. The antibody recognised the intracellular domain of HyJagged when it was expressed in E.coli after SDS-PAGE and Western blotting (Additional file 1A). In addition, on a Western blot with a vesicle fraction from Hydra the antibody recognised a band at an apparent molecular weight of $130 \mathrm{kDa}$. This is larger than the HyJagged primary sequence suggests $(96 \mathrm{kDa})$, most probably due to post-translational modification of mature HyJagged. Heavy glycosylation of EGF repeats is well documented for Notch ligands (recently reviewed in [15]).

The anti-JAG-IC antibody also detected HyJagged in immunofluorescence experiments, when we expressed it as GFP fusion protein in human HEK293T cells. This is shown in Additional file $1 \mathrm{D}-\mathrm{G}$. In a transient transfection experiment in HEK293T cells HyJagged-GFP did not reach the membrane but was instead trapped in the ER as can be seen by strong staining of the nuclear envelope. This incorrect distribution of HyJagged is most probably due to incomplete post-translational processing of the hydra protein in human cells [16].
Nevertheless this experiment clearly shows that the antibody recognises HyJagged specifically in immunofluorescence. It did not react with any other human protein in HEK293T cells. We therefore used this antibody for immunofluorescence on Hydra whole mounts. Here it stained membranes and punctuate structures in the cytoplasm of epithelial cells all over the animal (Figure 8). A weak increase of the staining in comparison with the surrounding tissue was detected in budding animals at stage 9 at the base of the bud in the ectoderm of the parental animal (Figure 9). This is in accordance with the in situ hybridisation data, which indicated strong mRNA expression in this region.

In addition to epithelial cells, cells of the interstitial cell lineage were also stained with the antibody. This was seen especially in nerve cells of the basal disc (Figure 10). Co-immunofluorescence experiments with the anti-JAG-IC- and anti-Nv1-antibodies were performed in order to relate HyJagged-positive cells to a specific cell type. The anti-Nv1-antibody is specific for sensory neurons in the tentacles and ganglion cells in the peduncle [17]. Co-staining with anti-JAG-IC showed that these ganglion cells also contained HyJagged, but in addition, HyJagged was also present in $\mathrm{Nv}-1$ negative neurons (Figure 11).

In order to identify HyJagged proteins in cells of the nematocyte line we used a rat monoclonal antibody against HyZic protein since Hyzic mRNA is known to

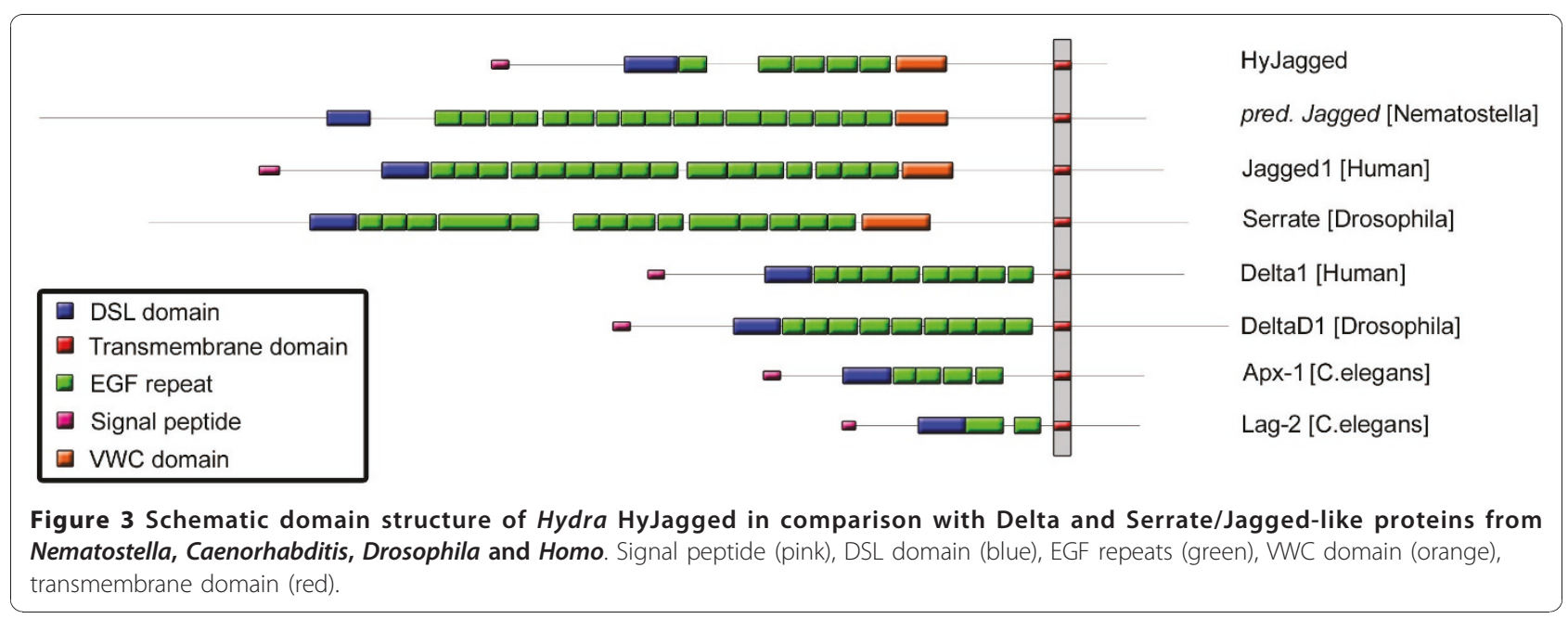




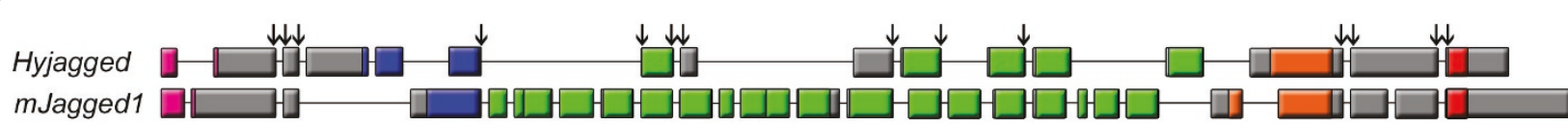

\begin{tabular}{|ll|}
\hline Signal peptide & $\square$ WWC domain \\
$\square$ EGF repeat & $\square$ Transmembrane domain \\
$\square$ DSL domain & $\square$ Exon \\
& - Intron
\end{tabular}

Figure 4 Schematic representation of the exon-intron structure of Hyjagged (Hydra) in comparison to mJagged1 (mouse). Coding regions for the different protein domains are shown in colour: signal peptide (pink), DSL domain (blue), EGF repeats (green), VWC domain (orange), transmembrane domain (red), non-conserved exon regions (grey). Introns are not to scale (black lines). Conserved exon-intronboundaries are marked with arrows.

be expressed in proliferating nematocyte precursors [18]. Rats were immunized with HyZic protein that we produced in E.coli. The resulting monoclonal antibody antiZIC7A12 detected the recombinant protein on Western blots. Moreoever, it stained a band of $46 \mathrm{kDa}$, which corresponds to the predicted size of HyZic in Western blots from hydra lysates (Additional file 2). In addition, in immunofluorescence experiments it recognised a HyZic-GFP fusion protein when expressed in hydra cells (see Additional file 2). On Hydra whole mounts the anti-ZIC7A12 antibody strongly stained single and double interstitial cells and nests of nematoblasts before their exit from mitosis. Weaker staining was observed in post-mitotic nematoblasts, which already had formed a small vacuole. In further developed nematocytes HyZic was not detected anymore. This distribution of HyZic protein in Hydra is in good agreement with published data about the localisation of its mRNA in proliferating nematoblasts [18]. Figure 12 shows that single and pairs of interstitial cells highlighted with the anti-ZIC7A12 antibody also contained HyJagged in a punctuate pattern. This was also the case in proliferating nematoblasts. However, in finally differentiated nematocytes negative for HyZic very strong HyJagged staining was observed (Figure 12 Q-T, nc). In conclusion, while all cells of the nematocyte line seem to have HyJagged protein, its abundance increases in terminally differentiated cells.

Finally, we wanted to compare the cellular localisation of HyJagged with that of HvNotch. To this end we raised an antibody in chicken against $\mathrm{HvN}^{\Delta \mathrm{E}}$ (the Hydra Notch receptor HvNotch without its extracellular
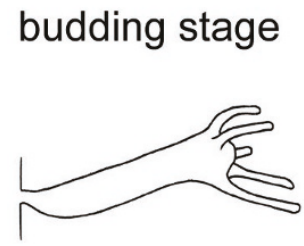

8
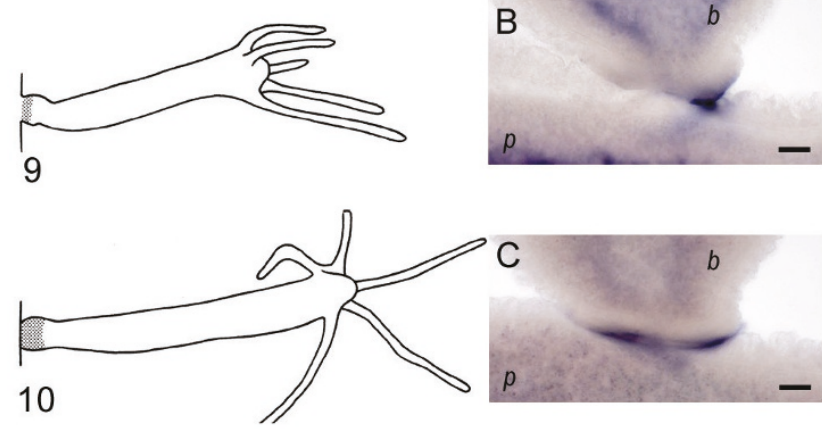

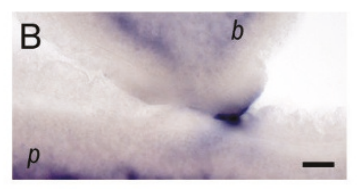

kringelchen
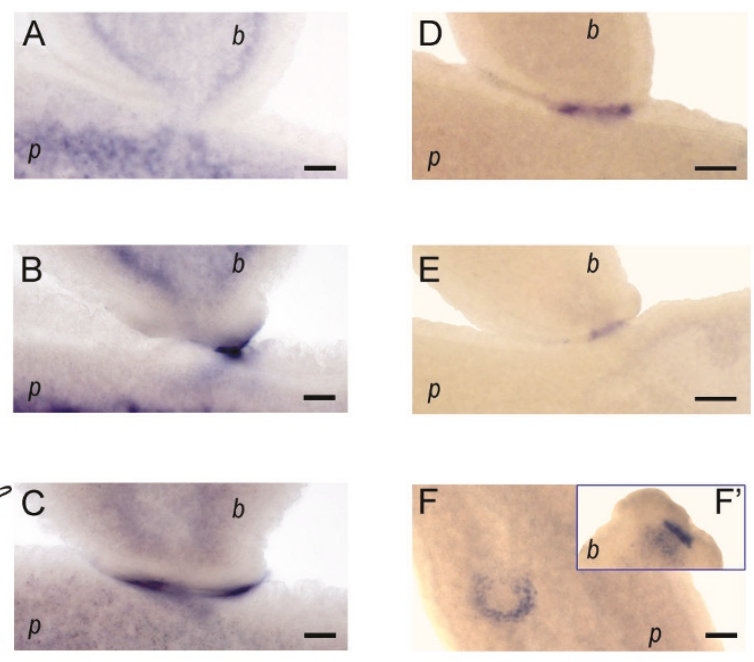

Figure 5 Whole mount in situ hybridisation for Hyjagged and kringelchen during late budding stages. Left hand panel: Budding stages 8 , 9 and 10 according to [31]; (A-C) in situ hybridisation for Hyjagged, (D-F') in situ hybridisation for kringelchen from [10]; (F') foot of bud that fell off during staining procedure; $(p)$ parent animal; (b) bud. NBT/BCIP (Roche) was used for staining reactions (blue signals). Scale bars: $20 \mu m$. 


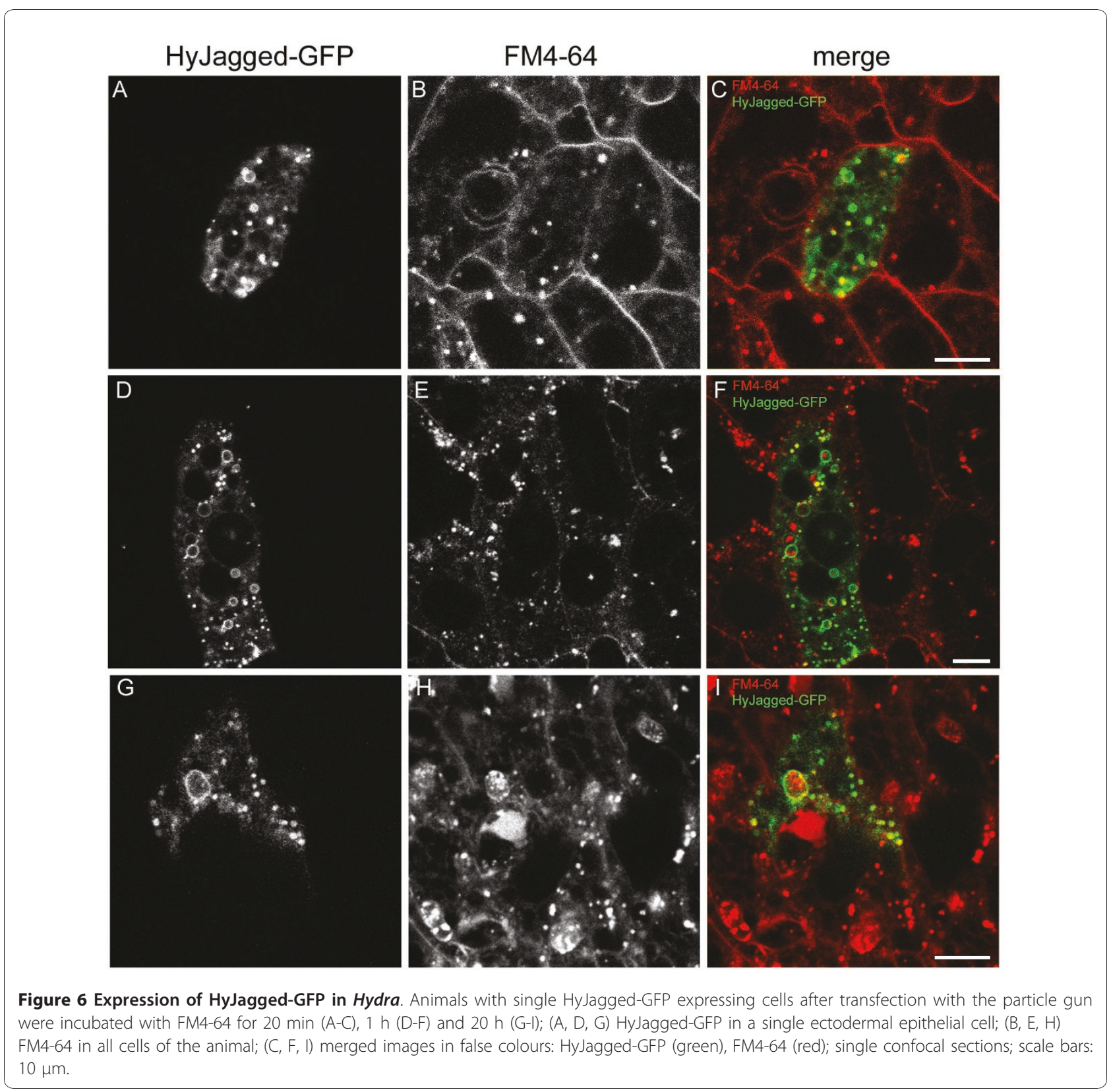

domain) after its expression in E.coli. It detected $\mathrm{HvN}^{\Delta \mathrm{E}}$ after expression in E.coli by SDS-PAGE and Western blotting down to a concentration of $8,9 \mathrm{ng}$ (see Additional file 3A). Furthermore it recognised overexpressed HvNotch-GFP fusion protein in human HEK293T cells in immunofluorescence experiments (see Additional file 3). We thus used it for co-immunofluorescence staining on Hydra whole mounts together with the anti-JAG-IC antibody. Both antibodies stained membranes of epithelial cells and cells in the interstitial spaces, however, the patterns did not completely overlap. Moreover, both antibodies stained punctuate structures in the cytoplasm. From co-localisation experiments of live images where HvNotch and HyJagged clearly co-localised with the membrane selective dye FM4-64 we concluded that these punctae most likely correspond to endosomes. However, HyJagged- and HvNotch antibody signals in endosomes do not generally co-localise. Moreover, HyJagged signals appear stronger localised on the membranes in comparison with Notch, this is especially obvious in interstitial cells (Figure 13).

\section{Discussion}

In this work we have identified a potential ligand for HvNotch in Hydra, HyJagged. It has the same modular structure as Notch ligands from higher animals and the 


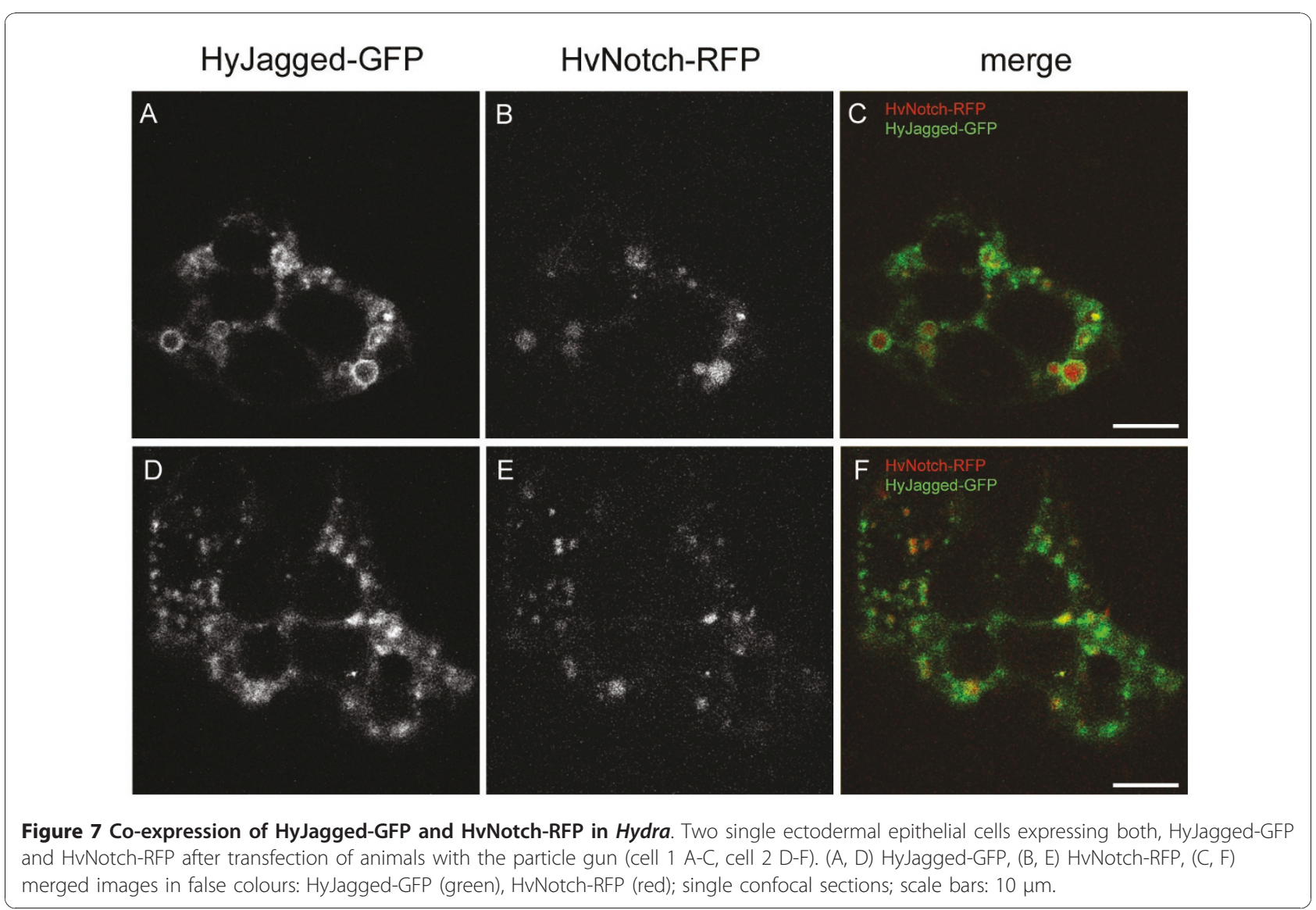

closely related Cnidarian Nematostella, which is also reflected in the conserved exon-intron structure of its gene between Hydra and mouse. The protein includes a DSL domain, which is responsible for the interaction with the extracellular EGF repeats of the Notch receptors in flies and mammals [11]. Moreover, HyJagged possesses a relatively small number of EGF repeats and a transmembrane domain. Comparison of the abundance of EGF repeats in Notch ligands and receptors shows some interesting similarities: Species with large extracellular domains in their Notch receptors (e.g. Nematostella, Drosophila and mouse) also have a high number of EGF repeats in their Serrate/Jagged-like proteins (however not in Delta) and vice versa (Figure 3 and [5]).

Thus, although we have not provided experimental evidence, we suggest that HyJagged constitutes the only canonical Notch ligand in Hydra. A second gene encoding a DSL domain is also present in Hydra. It has been identified previously and was shown to be expressed in gland cells [19]. The resulting protein is 332 amino acids long, has a signal peptide and a DSL domain and thus shows some structural homology with DSL2, a soluble Notch ligand from C.elegans. It would be interesting to see whether this protein is involved in Notch signalling in Hydra.

In situ hybridisation showed that Hyjagged was not visibly expressed on the mRNA level in intact Hydra with the exception of a very strong upregulation at budding stage 9. We have previously described that Notch signalling is important for late budding stages in Hydra. Whilst as early as at budding stage 5-6 HvWnt8 and the Hydra FGFR-homolog kringelchen demarcate the boundary between the parent animal and the bud $[20,21]$ budding cannot be completed without Notch signalling. The gene expression zone of kringelchen remains diffuse and a crucial metalloprotease, MMP-A3 is not induced. Thus the bud cannot constrict and does not form a foot. Two stripes of gene expression are required for correct patterning of the bud, one leading to constriction involving MMP-A3 and the other leading to differentiation of the buds foot cells involving expression of foot specific genes such as ppod-1. For these to form we proposed a model including mutual inhibition and lateral activation on the basis of Notch signalling at this boundary [10].

Our model required that cells which express kringelchen at the boundary express a Notch ligand. The data 


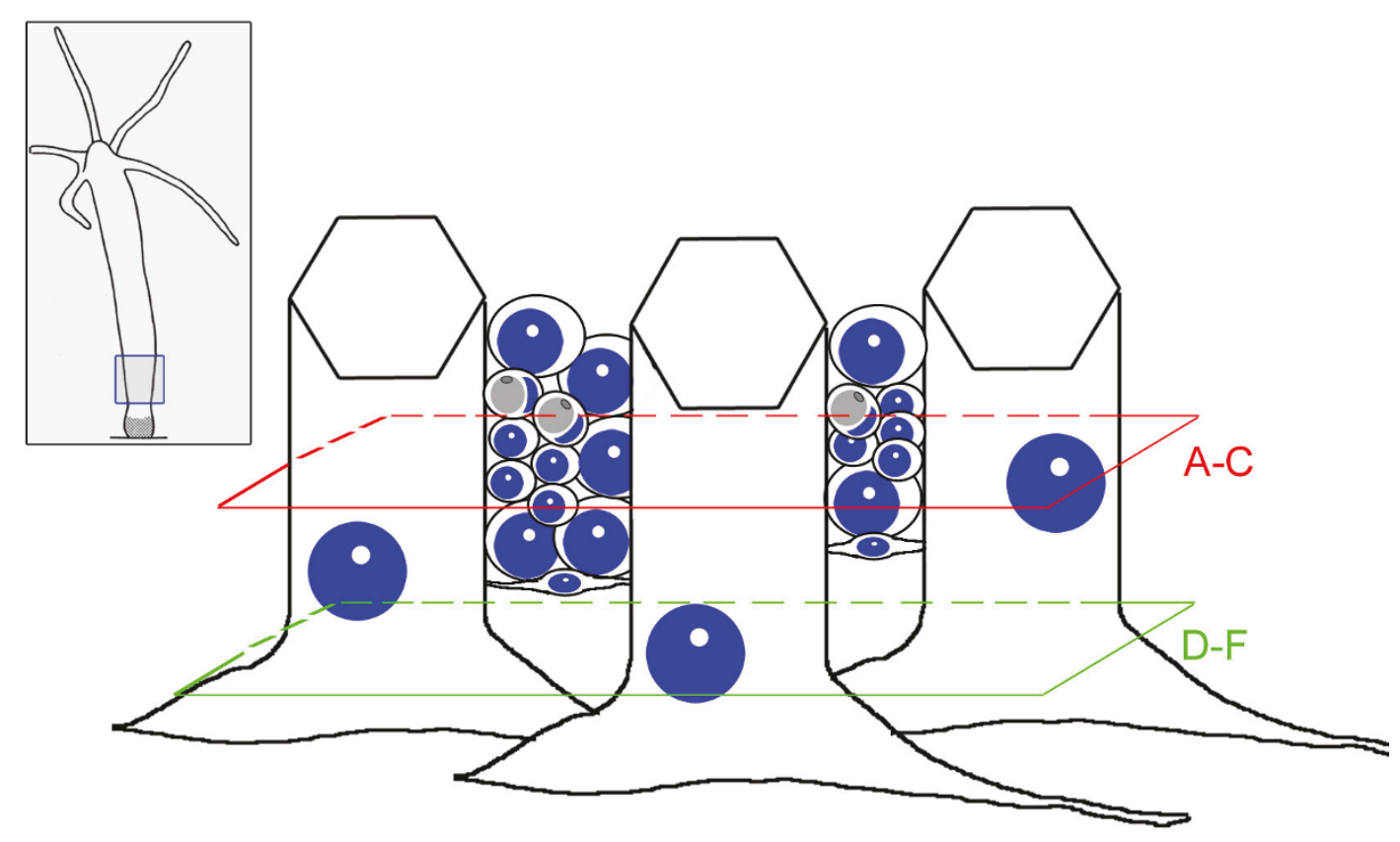

TO-PRO3
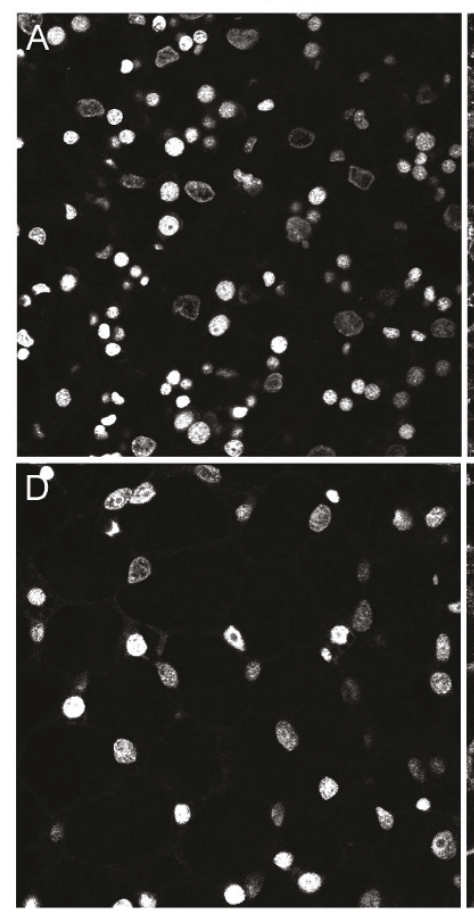

anti-JAG-IC
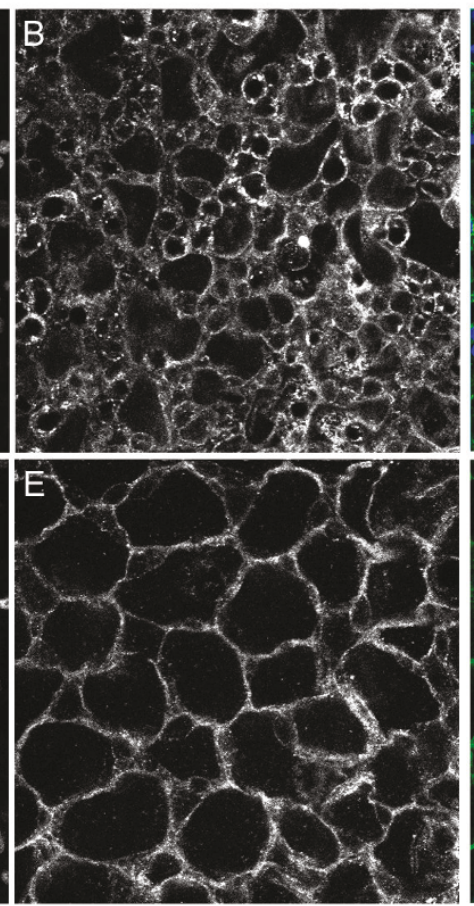

merge
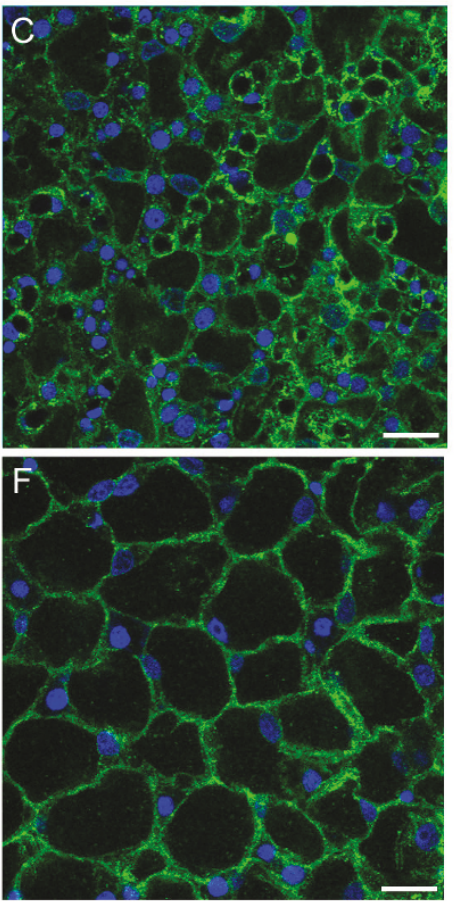

Figure 8 Immunofluorescence of Hydra whole mounts with the anti-JAG-IC antibody. Upper panel left: schematic representation of an adult hydra, the region imaged in lower panel is indicated, upper panel, right: schematic drawing of cells that were imaged including ectodermal epithelial cells, interstitial cells, nematoblasts, nematocytes and nerve cells; positions of confocal sections are boxed in red (A-C) and green (D-F). (A, D) DNA staining of single confocal sections with TO-PRO3, (B, E) anti-JAG-IC staining, (C, F) merged images in false colours: DNA (blue), anti-JAG-IC staining (green); scale bars: $20 \mu \mathrm{m}$. 


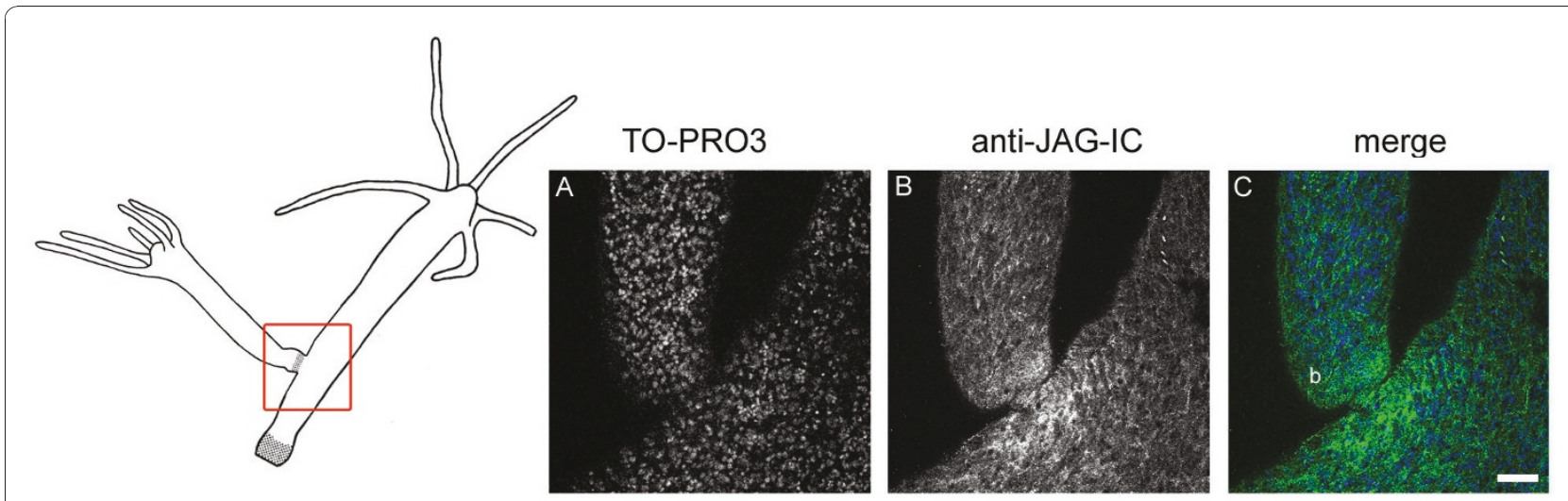

Figure 9 Staining of HyJagged during budding. Left hand panel: Schematic of an adult hydra with bud at stage 9 , region imaged in A-C is indicated; (A) DNA staining of single confocal section with TO-PRO3, (B) anti-JAG-IC staining, (C) merged images of all channels in false colours: DNA (blue), anti-JAG-IC staining (green); scale bar: $50 \mu \mathrm{m}$.

shown here are partially in accordance with this assumption because Hyjagged is expressed in cells that also express kringelchen at the boundary between parent and bud. However, the timing of this upregulation is unexpected. While constriction begins in budding stage
8, Hyjagged mRNA could only be detected at the beginning of budding stage 9. Hyjagged expression during earlier budding stages probably occurs in too low amounts to be detectable by in situ hybridisation experiments. Antibody staining clearly shows the presence of

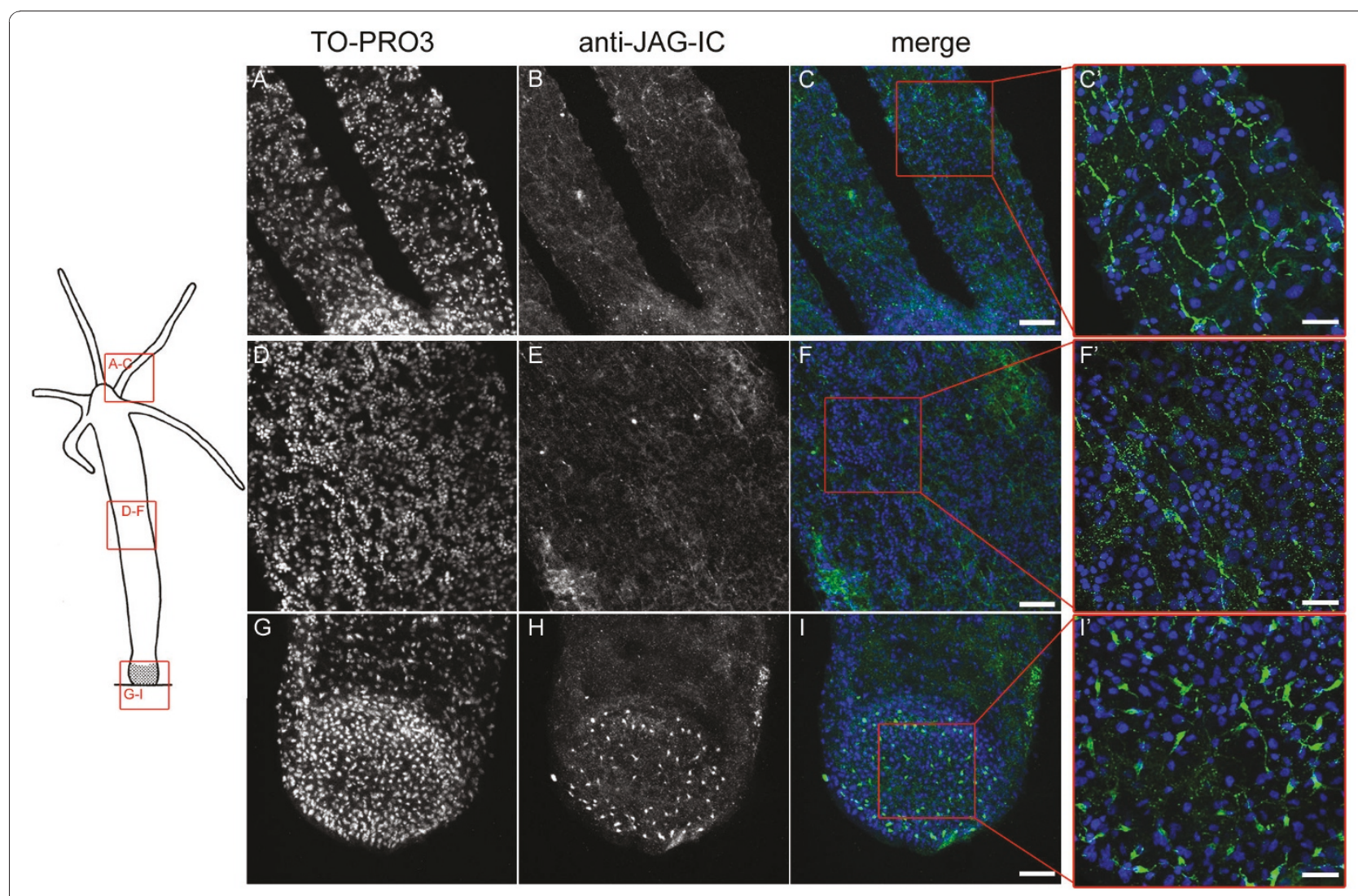

Figure 10 Nerve cell staining of HyJagged. Left hand panel: Schematic representation of an adult hydra; regions imaged in A-I are indicated; $(A, D, G)$ DNA staining of stacks of confocal sections with TO-PRO3, $(B, E, H)$ anti-JAG-IC staining, $\left(C, F, I, C^{\prime}, F^{\prime}, I^{\prime}\right)$ merged images in false colours: DNA (blue), anti-JAG-IC staining (green); $C^{\prime} F^{\prime}$ and I' are magnifications of $C, F$ and I as indicated by red boxes; scale bars: (A-I) $50 \mu m,\left(C^{\prime}, F^{\prime}, I^{\prime}\right) 20$ $\mu \mathrm{m}$. 


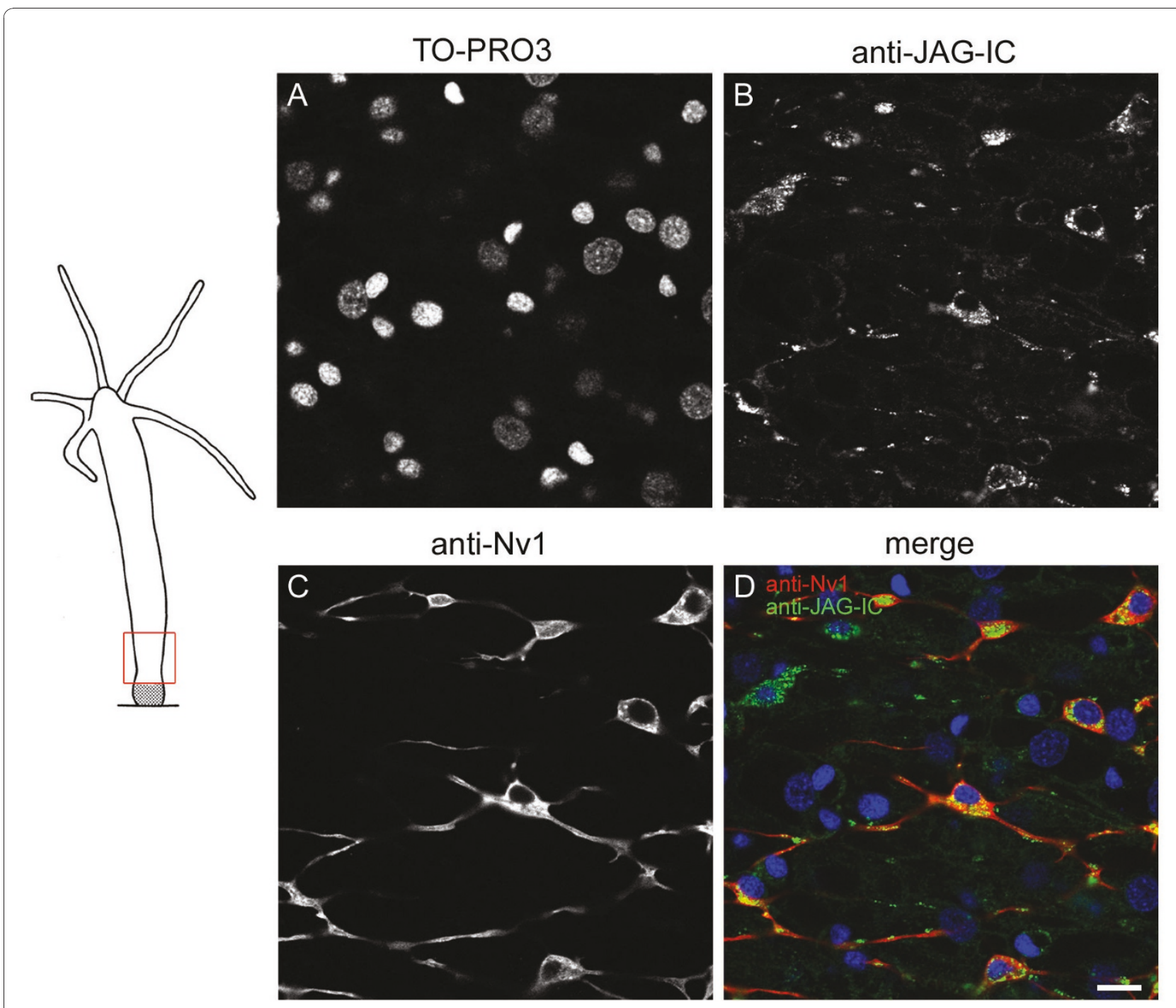

Figure 11 Co-immunofluorescence staining with anti-JAG-IC- and anti-Nv1-antibodies. Left hand panel: Schematic representation of an adult hydra with imaged region indicated; right hand panel: single confocal sections: (A) DNA staining with TO-PRO3, (B) anti-JAG-IC staining, (C) anti-Nv1 staining, (D) merged images of all channels in false colours: DNA (blue), anti-JAG-IC staining (green), anti-Nv1 staining (red); scale bar: $10 \mu \mathrm{m}$.

HyJagged at the basis of buds, however, only a weak increase in its level at this position in comparison with the remaining tissue is detectable (Figure 9). At this point we clearly have not used techniques suited to uncover precise quantitative differences in the amounts of HyJagged mRNA and protein at the cellular level during the final stages of budding. Therefore we cannot exclude the possibility that the observed requirement for Notch signalling at the boundary between parent and bud involves a mechanism that does not include a direct HyJagged-HvNotch interaction.

In contrast to the generally undetectable levels of mRNA expression outside the boundary between parent and bud, HyJagged protein is clearly present in all cells of the animals. The same is true for HvNotch. Although this makes it difficult to conclude whether there is active Notch signalling going on, the presence of the proteins is not unexpected. Notch signalling is highly regulated by factors involved in post-translational modification of the receptors (e.g. Fringe) [22], by the activity of metalloproteases like ADAM [23] and of presenilin as catalytic subunit of the $\gamma$-secretase complex and also by endocytosis of both, the Notch receptors and the ligands $[24,25]$. Endocytosis is part of a mechanism that leads to mutual inhibition of the signal sending and signal receiving cells. This means that signalling cells have higher levels of ligand but inhibit the propagation of Notch signals from adjacent cells and vice versa [26]. That way signalling can be induced by small differences in the concentration of receptors and ligands in this 


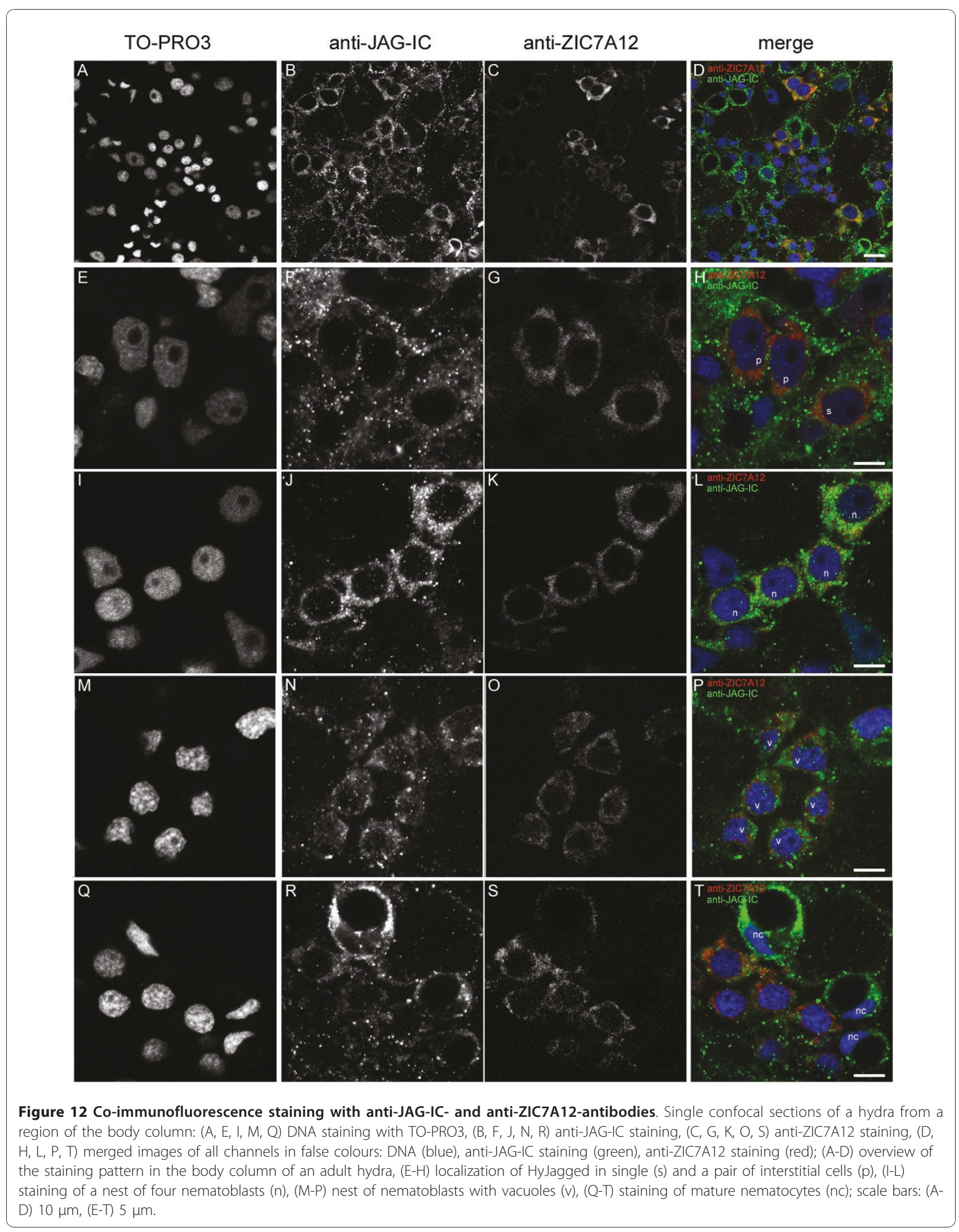



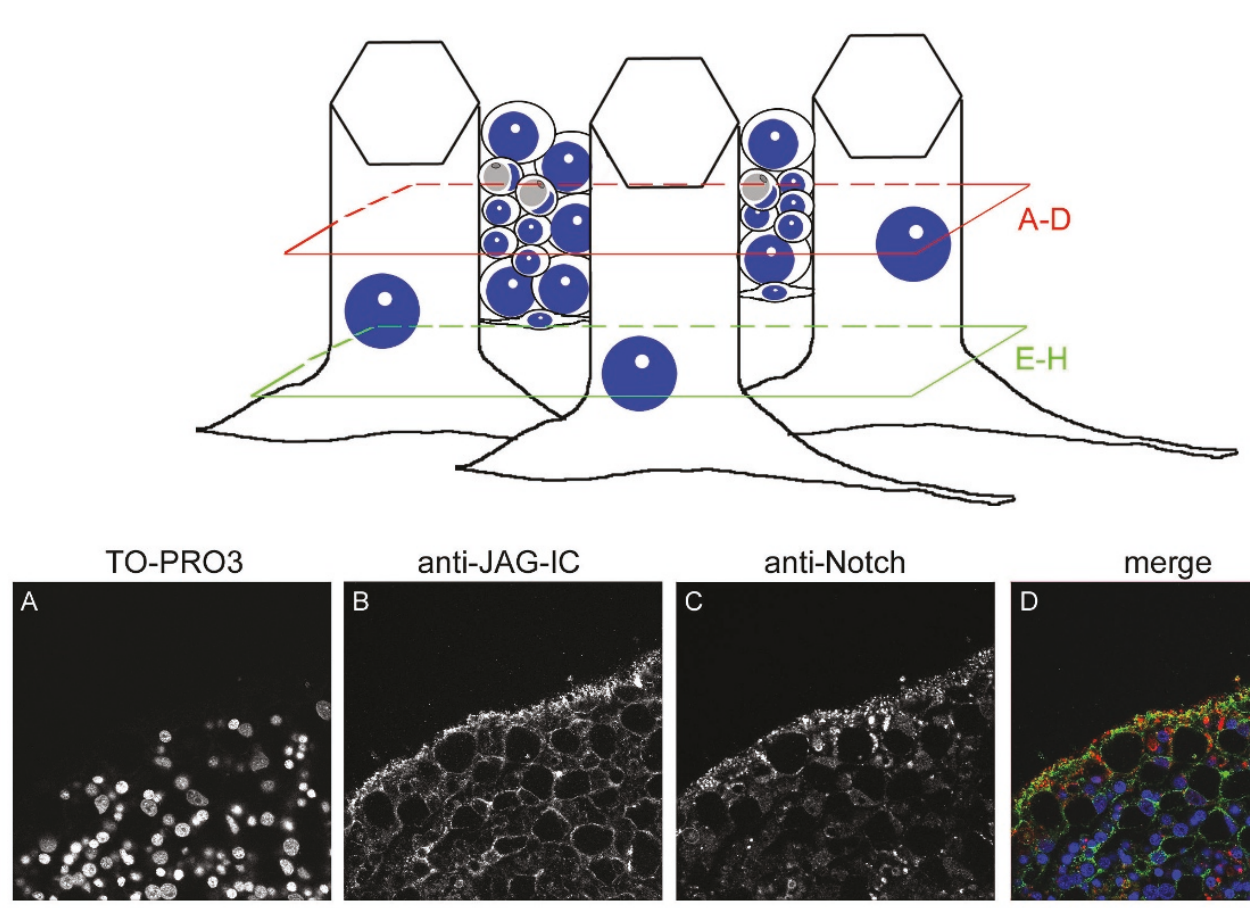

anti-JAG-IC
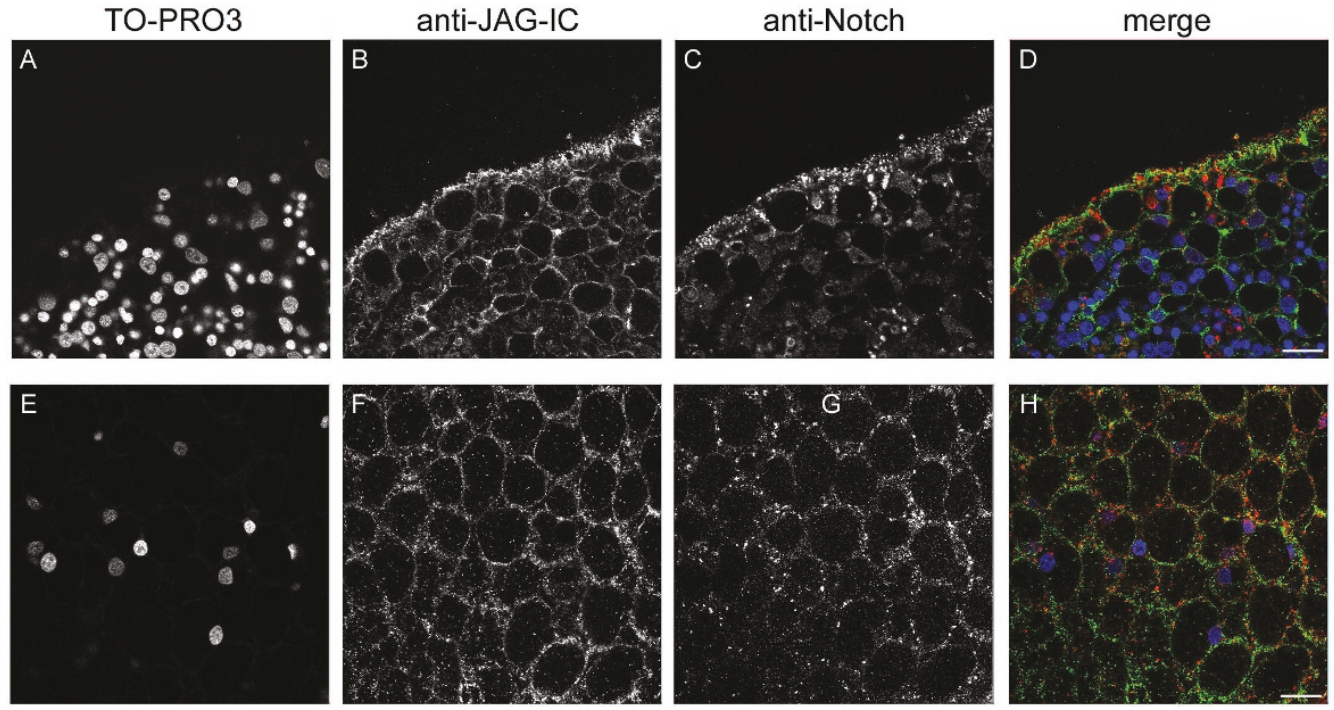

Figure 13 Co-immunofluorescence staining of Hydra whole mount with anti-JAG-IC- and anti-Notch-antibodies. Upper panel left: schematic representation of an adult hydra, the region imaged in lower panel is indicated; upper panel, right: schematic drawing of cells that were imaged including ectodermal epithelial cells, interstitial cells, nematoblasts, nematocytes and nerve cells; positions of confocal sections are boxed in red (A-D) and green (E-H). (A, E) DNA staining with TO-PRO3, (B, F) anti-JAG-IC staining, (C, G) anti-Notch staining, (D, H) merged images in false colours: DNA (blue), anti-JAG-IC staining (green), anti-Notch staining (red); single confocal sections; scale bars: $20 \mu \mathrm{m}$.

system, which might be hard to detect in immunofluorescence experiments [27]. We have shown that GFP/ RFP-tagged HyJagged and HvNotch are indeed localised in endosomes (this work and [5]). However, the fluorescently tagged protein did not completely co-localise with each other within these structures. Differences in the localisation of the endogeneous proteins were also seen in immunofluorescence experiments. HyJagged appeared stronger localised at membranes whereas HvNotch showed a slightly stronger staining of punctae in the vicinity of the membranes. In interstitial cells membrane staining was completely lacking with the HvNotch antibody.

In Hydra, Notch signalling might also be regulated through post-translational modification of receptor and ligand as genes encoding metalloproteases of the ADAM family, the glycosyltransferase Fringe and the ubiquitin ligase Mindbomb, which regulates endocytosis of Notch ligands, are present in the genome [12]. Their expression patterns might be conclusive in the future in order to understand the precise molecular mechanism by which Notch signalling exerts its profound impact on pattern formation and stem cell differentiation in Hydra.

\section{Conclusions}

We report here the identification of the Hyjagged gene, which encodes a protein with great similarity to canonical Notch ligands from worms, insects and vertebrates. Its mRNA is especially strongly expressed at the constriction site of budding animals, confirming the conserved role for Notch ligands during boundary formation. Furthermore, both HvNotch and HyJagged proteins are found in all cells of adult animals indicating a general role for Notch signalling in regulating cellular 
communication in Hydra. The differential distribution of both proteins in endosomes indicates that endosomal pathways may play an important role in modulating Notch signalling.

\section{Methods}

\section{Hydra culture}

Hydra vulgaris (Basel) was grown at a temperature of $18^{\circ} \mathrm{C}$ in hydra medium $\left(0.4 \mathrm{mM} \mathrm{CaCl} 2,0.6 \mathrm{mM} \mathrm{MgSO}_{4}\right.$, $0.5 \mathrm{mM} \mathrm{NaHCO} 3,0.08 \mathrm{mM} \mathrm{K}_{2} \mathrm{CO}_{3}$ ). The animals were fed regularly with freshly hatched Artemia nauplii.

\section{PCR amplification of Hyjagged sequences}

Hydra cDNA for RACE experiments was obtained with the GeneRacer Kit with Superscript III (Invitrogen). 5' and 3'RACE experiments were performed using the gene specific primers 5'-CCCATTTGTT GTGAGGC GTA AAGCTGATGT AAGTGC-3' and 5'-GGAGTTGCAA AATGTACAGA TGCATGGTGT GG-3'. Fulllength Hyjagged was then amplified from Hydra cDNA by PCR.

\section{Whole mount in situ hybridisation experiments}

Single whole mount in situ hybridisation experiments were carried out using Digoxigenin-labeled RNA probes as described before $[17,28]$.

\section{Construction of GFP and RFP fusion proteins}

Full-length Hvnotch was cloned into the NheI and SmaI sites of the HoTRed expression vector. Full-length Hyjagged as well as Hyzic were cloned into the modified EGFP expression vector HoTG(reen) [29] into the NheI and SmaI sites for overexpression from the Hydra actin promoter in hydra cells.

For expression in mammalian cells HvNotch and Hyjagged genes were cloned into the EcoRI and SmaI sites of the expression vector pEGFP (Clontech), leading to expression of C-terminally GFP-tagged proteins.

\section{Transfection of Hydra cells}

GFP- and RFP-constructs were introduced into hydra cells using a particle gun (Biorad) as described previously [29]. After 1-2 days cells expressing the GFP and RFP fusion proteins were clearly visible.

\section{Production of recombinant proteins}

To allow expression in E.coli the coding sequences for $H v N^{\Delta E}$ (HvNotch without its extracellular domain), HvNICD , Hyjagged-ICD, Hyzic, HyHes and Cnash were cloned into the vector pRSET (Invitrogen) using the BamHI and EcoRI sites for $H v N^{\Delta E}$, HvNICD, HyjaggedIC and Hyzic, and the EcoRI and XhoI sites for Cnash and HyHes.
Denatured $\mathrm{His}_{6}$-tagged-HyJagged-ICD, $-\mathrm{HvN}^{\Delta \mathrm{E}}$, -HvNICD, -HyZic, -HyHES and -CnASH were produced in E.coli and affinity-purified using nickel sepharose (Amersham Biosciences). Recombinant $\mathrm{HvN}^{\Delta \mathrm{E}}$ and HyZic were used for antibody production, recombinant HyJagged-ICD, HvNICD, HyZic, HyHES and CnASH were analysed by SDS-PAGE and Western Blot using anti-Notch (dilution 1:100), anti-JAG-IC (dilution 1:500), anti-ZIC7A12 (dilution 1:1), anti-HES (dilution 1:500) and anti-CNA7B10 (dilution 1:1) antibodies.

\section{Antibody production}

Anti-Notch antibody was produced in chicken by Davids Biotechnologie $\mathrm{GmbH}$ by immunisation with recombinant $\mathrm{HvN}^{\Delta \mathrm{E}}$. A portion of the resulting polyclonal antibody was then affinity purified.

For the anti-JAG-IC antibody a peptide corresponding to a stretch of the intracellular domain of HyJagged (VNKDNLKKGIFKTISRKS) was produced by Davids Biotechnologie $\mathrm{GmbH}$ and used for immunisation of rabbit. The resulting antibody was then affinity purified.

For the anti-HES antibody a peptide corresponding to a stretch of the region shortly before and the begin of the basic domain of HyHES (RHPMKEKRRANKPLLER) was produced by Davids Biotechnologie GmbH and used for immunisation of rabbit. The resulting antibody was then affinity purified.

Monoclonal anti-ZIC7A12- and anti-CNA7B10-antibodies were produced in rat as described in [30]. Recombinant HyZic and $\mathrm{CnASH}$ were used for immunisation.

\section{Cultivation and transfection of HEK293T}

Human embryonic kidney cells (293T) cells were cultured in DMEM (Sigma) supplemented with 10\% FCS and $5 \% \mathrm{Pen} /$ Strep at $37^{\circ} \mathrm{C}$ and $5 \% \mathrm{CO}_{2} .293 \mathrm{~T}$ cells were transfected using PEI pH 7,0.

\section{Antibody staining of HEK293T}

HEK293T cells at 70-80\% confluence were seeded on glass coverslips in 6-well culture plates and incubated for $24 \mathrm{~h}$ at $37^{\circ} \mathrm{C}$. After that the cells were transfected with the specific DNA. After $24 \mathrm{~h}$ the coverslips were washed twice with PBS, and the cells were fixed in 4\% PFA in PBS for 15 minutes at room temperature. After washing the cells again, they were permeabilized for 15 minutes with $1 \%$ Triton X-100 in PBS, washed twice with PBS and incubated in blocking solution (10\% FCS, $0,2 \%$ Tween 20, PBS) for one hour at room temperature. Cells were then incubated with primary antibody (antiNotch antibody (dilution 1:100) or anti-JAG-IC antibody (dilution 1:50)) for further 60 minutes at room temperature. After that, they were washed three times for 10 
minutes in washing solution (1\% BSA, 0,2\% Tween 20 , PBS) before they were incubated in secondary antibody for one hour at room temperature. Finally, cells were washed three times for 10 minutes with washing solution, incubated with TO-PRO 3 (Molecular probes, 1 $\mu \mathrm{g} / \mathrm{ml}$ in PBS) for 5 minutes and mounted on slides with Vectashield (Alexis Biochemicals).

\section{Subcellular fractionation}

500 hydra were dissociated into single cells in dissociation medium $(3.6 \mathrm{mM} \mathrm{KCl} ; 6 \mathrm{mM} \mathrm{CaCl} ; 1.2 \mathrm{mM}$ $\mathrm{MgSO}_{4} ; 6 \mathrm{mM}$ sodium citrate; $6 \mathrm{mM}$ sodium pyruvate; $6 \mathrm{mM}$ glucose; $12.5 \mathrm{mM}$ TES; and $50 \mathrm{mg} / \mathrm{ml}$ rifampicin, pH6.9) by pipetting. After centrifugation the resulting cell pellet was resuspended and incubated for 4 hours at $18^{\circ} \mathrm{C}$ on a rotator in $20 \mu \mathrm{M}$ of the proteasome inhibitor MG-132 (Sigma). The cells were then incubated on ice in $500 \mathrm{mM}$ Saccharose, $10 \mathrm{mM}$ Tris, $2 \mathrm{mM}$ EGTA $\mathrm{pH} 7,4,10 \mathrm{ng} / \mathrm{ml}$ Pepstatin A, $10 \mathrm{ng} / \mathrm{ml}$ Aprotinin, 10 $\mathrm{ng} / \mathrm{ml}$ Leupeptin, $0,5 \mathrm{mg} / \mathrm{ml}$ Pefablock for $20 \mathrm{~min}$ before homogenization with a Potter-Dounce homogenizer. The homogenate was differentially centrifuged. The $1000 \mathrm{~g}$ and $100.000 \mathrm{~g}$ pellets were separated by SDSPAGE and Western Blots were stained with the antiJAG-IC (dilution 1:500), rabbit preimmune serum (1:1000), anti-HES (dilution 1:500), anti-ZIC7A12 (dilution1:1) or anti-CNA7B10 (dilution1:1) respectively.

\section{Antibody staining of whole Hydra}

For membrane staining of endogenous HvNotch and endogenous HyJagged whole animals were relaxed with $2 \%$ urethane and fixed with PFA/EtOH (2\% PFA, 70\% $\mathrm{EtOH}, \mathrm{PBS})$ for 30 minutes. They were then washed twice for 5 minutes with PBS followed by an ethanol treatment. Therefore hydra were treated with $20 \%, 30 \%$, $40 \%, 50 \%, 75 \% \mathrm{EtOH}$ in PBS and $100 \% \mathrm{EtOH}$, followed by $75 \%, 50 \%, 40 \%, 30 \%$ and $20 \% \mathrm{EtOH}$ in PBS, each for 5 minutes. Further staining was performed as below, starting with permeabilization.

Other immunofluorescence staining experiments were performed by relaxing animals with $2 \%$ urethane and fixation with 4\% PFA in hydra medium for 1 hour. Hydra were then washed three times for 10 minutes with PBS before they were permeabilized for 15 minutes with $0,5 \%$ Triton X-100 in PBS. Animals were blocked for 15 minutes with $0,1 \%$ Triton $\mathrm{X}-100,1 \%$ BSA in PBS and incubated in anti-Notch antibody (dilution 1:100), anti-JAG-IC antibody (dilution 1:50), anti-Nv1 (dilution 1:2) or anti-ZIC7A12 (dilution 1:1) for $1 \mathrm{~h}$ at room temperature. Hydra were washed three times 10 minutes in PBS followed by incubation in secondary antibody for 2 $\mathrm{h}$ at room temperature. Before the animals were stained with TO-PRO3 (Molecular probes, $1 \mu \mathrm{g} / \mathrm{ml}$ in PBS) they were washed in PBS three times 10 minutes. Finally they were mounted on slides with Vectashield (Alexis Biochemicals).

\section{Confocal imaging}

Living animals with GFP-expressing cells were stained with FM4-64 (Molecular Probes) for detection of plasma membranes and endosomes. $1 \mu \mathrm{l}$ of $500 \mu \mathrm{M}$ FM4-64 in hydra medium was injected into the gastric cavity of Hydra. The animals were then incubated in $50 \mu \mathrm{M}$ FM4-64 in hydra medium for 20 minutes to 20 hours.

Living animals with GFP- and RFP-expressing cells were relaxed in $2 \%$ urethane and scanned immediately.

Light optical serial sections were acquired with a Leica (Leica Microsystems, Wetzlar, Germany) TCS SP confocal laser-scanning microscope equipped with an oil immersion Plan-Apochromat 100/1.4 NA objective lens. Fluorochromes were visualized with an argon laser with an excitation wavelength of $488 \mathrm{~nm}$ and emission filters of 520-540 nm for EGFP and Alexa488 and 640-760 nm for FM4-64, and with a helium-neon laser with an excitation wavelength of $633 \mathrm{~nm}$ and emission filter of 660$760 \mathrm{~nm}$ for TO-PRO3. For Cy3 and RFP the excitation wavelength was $561 \mathrm{~nm}$ and an emission filter of 570$580 \mathrm{~nm}$ was used. Image resolution was $512 \times 512$ pixel. The 8-bit grey scale single-channel images were overlaid to an RGB image assigning false color to each channel, and then assembled into tables using Adobe Photoshop 10.0 and Image $1.37 \mathrm{k}$ software.

\section{Accession numbers}

GenBank accession numbers for genes and proteins used in alignments and domain structures are as follows:

HyJagged (JN036823); Mouse Jagged1 (NP_038850); Human Jagged1 (AAC51731); Human Delta-like1 (NP_005609); Drosophila Serrate (CAA40148); Drosophila DeltaD1 (AAR21456); C.elegans Apx-1 (NP_503882); C.elegans Lag-2 (NP_503877); Hydra HvNotch (ABV68547).

\section{Additional material}

\footnotetext{
Additional file 1: Testing of rabbit anti-JAG-IC peptide antibody. (AC) Western Blot after SDS-PAGE with bacterial lysates from E.coli expressing HyJagged-ICD (10 kDa) from pRSET (lanes labelled R JAG-IC $250 \mathrm{ng}$ ) and with vesicle fraction from hydra homogenates of 125 animals (lanes labelled $V 125$ a) probed with anti-JAG-IC antibody (A); Control with rabbit pre-immune serum (B); (C) Control Western blot probed with an unrelated rabbit antibody. This antibody had been raised against a peptide derived from Hydra HES and recognises HyHES (25 $\mathrm{kDa}$ ) in bacterial lysates from E.coli expressing HyHES from pREST (lane RHyHES 50 ng). (D-G) HEK293T cells expressing HyJagged-GFP from pCDNA3; (D) DNA staining with TO-PRO3, (E) HyJagged-GFP, (F) anti-JAGIC staining, (G) merged images in false colours: DNA (blue), HyJaggedGFP (green), anti-JAG-IC staining (red); Confocal sections; scale bar: $5 \mu \mathrm{m}$.

Additional file 2: Characterization of anti-ZIC7A12 antibody. (A, B) Western blot after SDS-PAGE of bacterial lysates expressing HyZic from pRSET (lanes recomb. HyZic $50 \mathrm{ng}$ and $10 \mathrm{ng}$ ) and lysates from hydra
} 
cells (lanes Hydra Ly) probed with monoclonal rat antibody anti-ZIC7A12 (A). Control with a rat $\lg \mathrm{G}$ that had been raised against $\mathrm{CnASH}$ (B). This antibody recognises a band below $43 \mathrm{kDa}$ in hydra lysates. The antiZIC7A12 recognises a band at $46 \mathrm{kDa}$, which corresponds to the predicted size for HyZic. (C-F) Single hydra epithelial cell ectopically expressing HyZic-GFP fusion protein from HotG after transfection of the animals with particle gun. (C) DNA staining with TO-PRO3, (D) HyZic-GFP, (E) anti-ZIC7A12 staining, (F) merged images in false colours: DNA (blue), HyZic-GFP (green), anti-ZIC7A12 staining (red); Confocal sections; scale bar: $2 \mu \mathrm{m}$.

Additional file 3: Characterisation of anti-Notch antibody. (A-C) Western Blot after SDS-PAGE of lysates from E.coli expressing myc tagged $\mathrm{HVN}^{\Delta E}(49 \mathrm{kDa})$ from pRSET probed with anti-Notch antibody (A), probed with chicken preimmune serum (B), probed with anti-myc antibody (C); arrows indicate HvN ${ }^{\Delta \mathrm{E}}$ and two apparent degradation products; (D-G) HEK293T cells expressing HvNotch-GFP from pcDNA3. (D) DNA staining with TO-PRO3, (E) HvNotch-GFP, (F) anti-Notch antibody staining (G) merged images in false colours: DNA (blue), HvNotch-GFP (green), antiNotch staining (red); Confocal sections; scale bar: 5 um.

\section{Acknowledgements}

We thank Prof. Charles N. David for assistance during database searches of the Hydra genome. We also thank Prof. Charles N. David and Prof. Harry MacWilliams for helpful discussions. We furthermore thank Dr. Olga Alexandrova for assistance with immunofluorescence stainings and confocal microscopy. The study was supported by grants BO1748-2 and BO1748-5 from the Deutsche Forschungsgemeinschaft awarded to A.B.

\section{Author details}

'Department of Biology 2, Ludwig-Maximilians-Universität München, Munich, Germany. ${ }^{2}$ Institute for Neuroscience, Innsbruck Medical University, Innsbruck, Austria. ${ }^{3}$ Institute for Molecular Immunology (IMI), Helmholtz Zentrum München, Munich, Germany.

\section{Authors' contributions}

AP isolated and characterised the Hydra Jagged homolog and carried out phylogenetic analysis, in situ hybridisations and protein localization studies. SM participated in in situ hybridisation, immunofluorescence experiments and Western blotting of subcellular fractions. EK produced the anti-ZIC7A12 monoclonal antibody. BL produced the protein for immunization of chicken and tested the anti-Notch antibody. ST participated in subcellular fractionation and in situ hybridisation. $A B$ conceived and coordinated the study. $A P$ and $A B$ drafted the manuscript. All authors read and approved it.

Received: 23 November 2010 Accepted: 7 September 2011

Published: 7 September 2011

\section{References}

1. Hobmayer B, Rentzsch F, Kuhn K, Happel CM, von Laue CC, Snyder P, Rothbächer $U$, Holstein TW: WNT signalling molecules act in axis formation in the diploblastic metazoan Hydra. Nature 2000, 407:186-189.

2. Minobe S, Fei K, Sarras M Jr, Werle M: Identification and characterization of the epithelial polarity receptor "Frizzled" in Hydra vulgaris. Development Genes and Evolution 2000, 210:258-262.

3. Steele RE: Developmental Signaling in Hydra: What does it take to build a "simple" animal? Developmental Biology 1996, 248:199-219.

4. Hobmayer B, Rentzsch F, Holstein TW: Identification and expression of HySmad1, a member oft he R-Smad family of TGFbeta signal transducers, in the diploblastic metazoan Hydra. Development Genes and Evolution 2001, 211:597-602.

5. Käsbauer T, Towb P, Alexandrova O, David CN, Dall'Armi E, Staudigl A, Stiening B, Böttger A: The Notch signalling pathway in the cnidarian Hydra. Developmental Biology 2007, 303:376-390.

6. Bode HR: The interstitial cell lineage of hydra: a stem cell system that arose early in evolution. Journal of Cell Science 1996, 109:1155-1164.

7. Bosch TCG, David CN: Stem cells of Hydra magnipapillata can differentiate into somatic cells and germ line cells. Developmental Biology 1987, 121:182-191.
8. David CN, Gierer A: Cell cycle kinetics and development of Hydra attenuate. III. Nerve and nematocyte differentiation. Journal of Cell Science 1974, 16:359-375.

9. David CN, Murphy S: Characterization of interstitial stem cell in Hydra by cloning. Developmental Biology 1977, 58:372-383.

10. Münder S, Käsbauer T, Prexl A, Aufschnaiter R, Towb P, Böttger A: Notch signalling defines critical boundary during budding in Hydra. Developmental Biology 2010, 344:331-345.

11. Rebay I, Fleming RJ, Fehon RG, Chebas L, Chebas P, Artavanis-Tsakonas S: Specific EGF repeats of Notch mediate interactions with Delta and Serrate: implications for Notch as a multifunctional receptor. Cell 1991, 67:687-699.

12. Chapman J, et al: The dynamic genome of Hydra. Nature 2010, 464:592-596.

13. Tax E, Yeargers JJ, Thomas JH: Sequence of C.elegans lag-2 reveals a cellsignalling domain shared with Delta and Serrate of Drosophila. Nature 1994, 368:150-154.

14. Vida TA, Emr SD: A new vital stain for visualizing vacuolar membrane dynamics and endocytosis in yeast. Journal of Cell Biology 1995, 128:779-792.

15. Stanley P, Okajima T: Roles of glycosylation in Notch signaling. Current Topics in Developmental Biology 92:131-164.

16. Okajima T, Xu A, Lei L, Irvine KD: Chaperone activity of protein OFucosyltransferase 1 promotes Notch receptor folding. Science 2005, 307:1599-1603.

17. Hobmayer B, Holstein TW, David CN: Tentacle morphogenesis in hydra, I. The role of head activator. Development 1990, 109:887-895.

18. Lindgens D, Holstein TW, Technau U: Hyzic, the Hydra homolog of the zic/ odd-paired gene, is involved in the early specification of the sensory nematocytes. Development 2004, 131:191-201.

19. Hwang J, Ohyanagi H, Hayakawa S, Osato N, Nishimiya-Fujisawa C, Ikeo K, David C, Fujisawa T, Gojobori T: The evolutionary emergence of cell typespecific genes inferred from the gene expression analysis of Hydra. PNAS 2007, 104:14735-14740.

20. Philipp I, Aufschnaiter R, Özbek S, Pontasch S, Jenewein M, Watanabe $H$, Rentzsch F, Holstein T, Hobmayer B: Wnt/b-Catenin and noncanonical Wnt signaling interact in tissue evagination in the simple eumetazoan Hydra. PNAS 2009, 106:4290-4295.

21. Sudhop S, Coulier F, Bieller A, Vogt A, Hotz T, Hassel M: Signalling by the FGFR-like tyrosine kinase, Kringelchen, is essential for bud detachment in Hydra vulgaris. Development 2004, 131:4001-4011.

22. Brückner $K$, Perez $L$, Clausen $H$, Cohen S: Glycosyltransferase activity of Fringe modulates Notch-Delta interactions. Nature 2000, 406:411-415.

23. Brou C, Logeat F, Gupta N, Bessia C, LeBail O, Doedens JR, Cumano A, Roux P, Black R, Israel A: A novel proteolytic cleavage involved in Notch signaling: the role of the disintegrin-metalloprotease TACE. Molecular Cell 2000, 5:207-216

24. Sakata T, Sakaguchi H, Tsuda L, Higashitani A, Aigaki T, Matsuno K, Hayashi S: Drosophila Nedd4 regulates endocytosis of Notch and suppresses its ligand-independent activation. Current Biology 2004, 14:2228-2236.

25. Parks A, Klueg K, Stout J, Muskavitch M: Ligand endocytosis drives dissociation and activation in the Notch pathway. Development 2000, 127:1373-1385.

26. Sprinzak D, Lakhanpal A, LeBon L, Santat L, Fontes M, Anderson G, GarciaOjalvo J, Elowitz M: Cis-interactions between Notch and Delta generate mutually exclusive signalling states. Nature 2010, 465:86-90.

27. Ward E, Zhou X, Riddiford L, Berg C, Ruohola-Baker H: Border of Notch activity establishes a boundary between the two dorsal appendage tube cell types. Developmental Biology 2006, 297:461-470.

28. Grens A, Mason E, Marsh JL, Bode HR: Evolutionary conservation of a cell fate specification gene: the Hydra achaete-scute homolog has proneural activity in Drosophila. Development 1995, 121:4027-4035.

29. Böttger A, Alexandrova O, Cikala M, Schade M, Herold M, David CN: GFP expression in Hydra : lessons from the particle gun. Development Genes and Evolution 2002, 212:302-305.

30. Rottach A, Kremmer E, Nowak D, Boisguerin P, Volkmer R, Cardoso MC, Leonhardt $\mathrm{H}$, Rothbauer U: Generation and characterization of a rat monoclonal antibody specific for PCNA. Hybridoma (Larchmt) 2008, 27:91-98. 
31. Otto JJ, Campbell RD: Budding in Hydra attenuate: bud stages and fate map. Journal of Experimental Zoology 1977, 200:417-428.

doi:10.1186/1471-2121-12-38

Cite this article as: Prexl et al:: The putative Notch ligand HyJagged is a

transmembrane protein present in all cell types of adult Hydra and

upregulated at the boundary between bud and parent. BMC Cell Biology 2011 12:38.

Submit your next manuscript to BioMed Central and take full advantage of:

- Convenient online submission

- Thorough peer review

- No space constraints or color figure charges

- Immediate publication on acceptance

- Inclusion in PubMed, CAS, Scopus and Google Scholar

- Research which is freely available for redistribution 